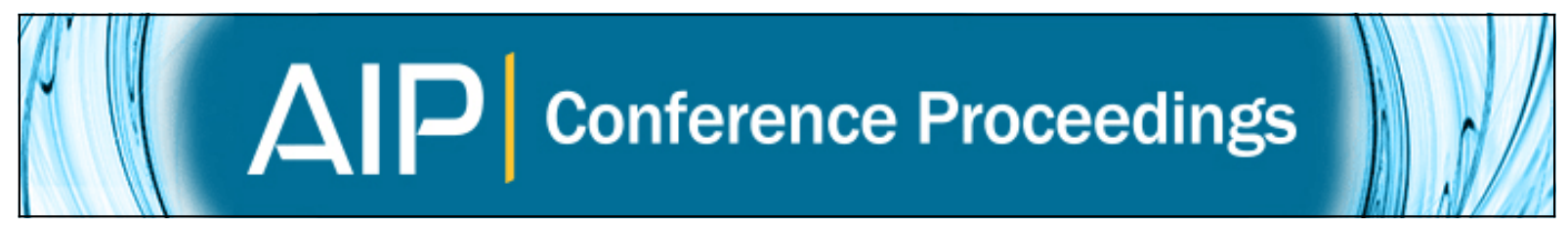

Idle and axial roll speed law trend effect in an industrial ring rolling process

Luca Giorleo, Elisabetta Ceretti, and Claudio Giardini

Citation: AIP Conference Proceedings 1769, 130006 (2016); doi: 10.1063/1.4963525

View online: http://dx.doi.org/10.1063/1.4963525

View Table of Contents: http://scitation.aip.org/content/aip/proceeding/aipcp/1769?ver=pdfcov

Published by the AIP Publishing

Articles you may be interested in

Numerical simulations supporting the process design of ring rolling processes

AIP Conf. Proc. 1532, 695 (2013); 10.1063/1.4806897

Finite element modelling of process-integrated powder coating by radial axial rolling of rings

AIP Conf. Proc. 1353, 339 (2011); 10.1063/1.3589538

Finite Element Modeling of Ring Rolling Processes

AIP Conf. Proc. 1252, 795 (2010); 10.1063/1.3457636

Numerical simulation of ring rolling process - Application to superalloy 718 parts

AIP Conf. Proc. 907, 1366 (2007); 10.1063/1.2729705

Industrial trends in computational chemistry

AIP Conf. Proc. 330, 807 (1995); 10.1063/1.47841 


\title{
Idle and Axial roll speed law trend effect in an industrial Ring Rolling process
}

\author{
Luca Giorleo $^{1, a}$, Elisabetta Ceretti ${ }^{1}$, Claudio Giardini ${ }^{2}$ \\ (1) University of Brescia - Dept. of Mechanical and Industrial Engineering - Brescia \\ (2) University of Bergamo - Dept. of Management, Information and Production Engineering - Bergamo \\ a)corresponding author: luca.giorleo@unibs.it
}

\begin{abstract}
In Ring Rolling process, to generate a seamless and axis symmetrical ring, two independent deformation processes simultaneously occur to reduce the starting ring cross section shape (width and height) in order to increase the diameter. How this shape changes during the whole deformation process greatly affects the produced ring quality and the loads and energy needed. The main problem is that the shape change is due to two deformation processes that occur in two different ring sections. The ring width reduction is realized in the cross section between the Idle and the Driver roll while the cross section deformed by the Axial rolls movement regulates the ring height. The main problem is that each roll speed law could be set independently from the others. In the industrial environment, a milling curve is introduced to correlate them to the ring section shape.

In order to enhance the knowledge on how the Idle and Axial roll speed laws affect the Ring Rolling process, in this work an industrial case study was modeled by a numerical approach. Different Idle and Axial roll speed laws (linearly decreasing, constant, linearly increasing), were designed and simulated. The results were analyzed in order to understand how each speed law trend affects the produced ring quality (higher diameter, lower fishtail) and the process performance (lower loads and energy required for manufacturing).
\end{abstract}

Keywords: Ring rolling, Roll speed law, FE modeling

\section{Introduction}

Ring Rolling is a particular rolling process characterized by a decreasing time-dependent rolls gap. Two different couples of rolls move toward each other in order to deform the width and the height of a starting hollow preform.
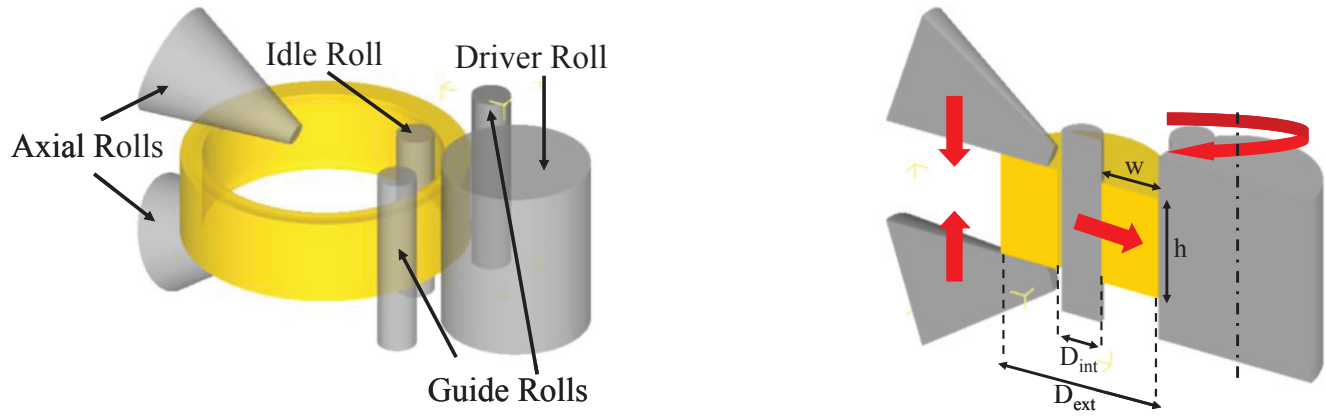

Figure 1: Main scheme of the process

As it can be observed in figure 1, two independent deformation processes simultaneously occur: one defined by the Idle roll displacement towards the Driver roll and the other defined by the Axial rolls movement. Because each roll displacement could be set independently from the other, in industrial environment a so-called "milling curve" is introduced. The aim of this curve is to define the shape of the ring during the deformation in order to ensure a correct ring production: in this curve, the instantaneous ring height is plotted as a function of the instantaneous width (figure 2.a). It's evident that it is theoretically possible to produce the same target ring starting from different milling curves, but an incorrect selection of the process parameters could generate undesired Ring Rolling defects, such as an excessive fishtail (figure 2.b), or an increase of the load and energy required. In literature, many authors focused their attention on the study and optimization of several and different Ring Rolling parameters: Lin et Zhi [1] developed a mathematical model to evaluate, as a function of the Driver and Idle roll diameters, the extremum Idle roll feeding speed needed to ensure a rotating and an expanding ring. Starting from these results Yan et al. [2] proposed a relationship to correlate the Idle speed to the ring outer diameter grown rate in case of cold Ring Rolling. Anjami et Basti [3], by means of FE approach, focused their research in finding the optimum dimensions of Driver and Idle rolls. Wang et al. [4] proposed a computer program based on the optimization of objective functions whose target is to control the motion of the Guide and Axial rolls, based on the result of virtual rolling. The effects of the Axial rolls motions on the Ring Rolling process was investigated by Hua et al. [5] showing a less uniform strain distribution increasing the Axial rolls feed rate; on the contrary the temperature distribution of the rolled ring becomes more homogeneous. 


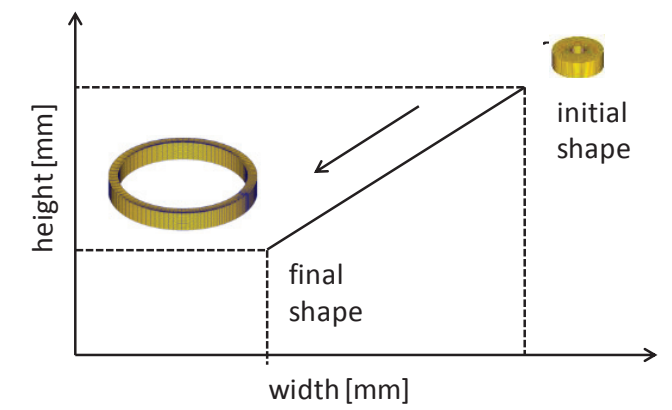

Figure 2.a: Milling curve for a Ring Rolling process

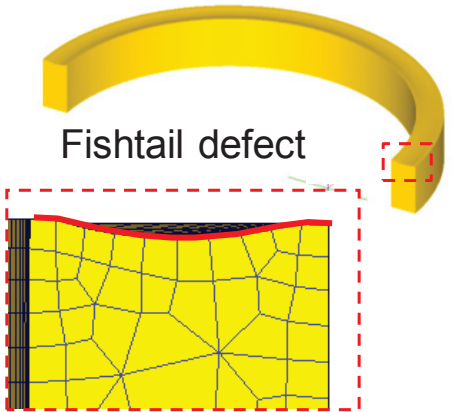

Figure 2.b: Fishtail defect

Guo et Yang [6] developed a set of mathematic correlations for the rolls speed to identify steady forming condition for the process based on a constant growth velocity condition of the ring. The model describes not only the mathematic correlations but also the reasonable ranges of the key process variables providing a useful method for the process design and optimization. In the last years Zhu et al. [7] focused their researches correlating, the Idle and Axial roll feed. They found that, taking the roundness, diameter precision, process stability, uniformities of deformation and temperature distribution into consideration, an optimum ratio of axial to radial feed amount equal to about 0.5. Parvizi A. [8] presented an upper bound solution to determine the ring rolling power and force. Giorleo et al. [9] focused the research to evaluate the preform geometry influence on an industrial ring rolling process; the results underlined that a decrease of the upset height could guarantee less energy and loads, less defect and material saving. Lee et al. [10] derived an advanced feasible forming condition for reducing ring spreads and maintaining process stability during radial-axial ring rolling process. Due to this approach, the deformation of the ring becomes uniform and the fishtail coefficient decreases as the growth velocity of the ring outer diameter increases within a proposed range of the advanced feasible forming condition.

However, despite these improvements, a lack of knowledge about the milling curve influence is still registered and most of the mathematical models available are based on a constant speed imposed to each roll.

In order to enhance the knowledge on how the Idle and Axial roll speed laws affect the Ring Rolling process, in this work an industrial case study was modeled by a numerical approach. Starting from preliminary research results [11] different Idle and Axial roll speed laws (linearly decreasing, constant, linearly increasing), were designed and simulated. The results were analyzed in order to understand how each speed law trend affects the produced ring quality (higher diameter, lower fishtail) and the process performance (lower loads and energy required for manufacturing).

\section{Modeling Set Up}

In Figure 3 the objects involved in the ring rolling simulation and the ring deformation as a function of the production time are summarized. The software, due to self-centring properties, allows to simulate the process without the Guide rolls. Moreover, due to the nature of the process, it is possible to reduce the number of elements, and so the computational time, by considering a symmetric model.
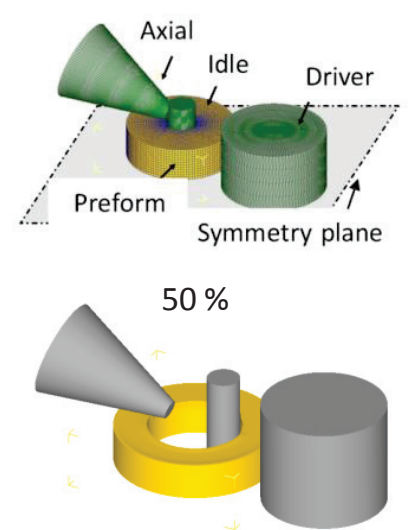

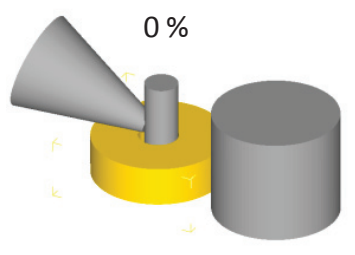

$75 \%$

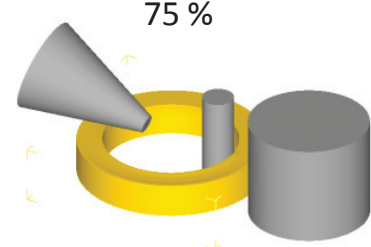

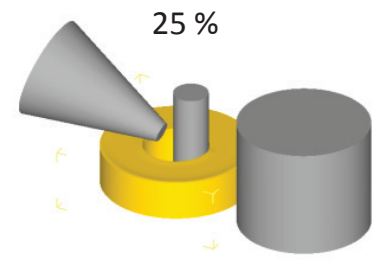

$100 \%$

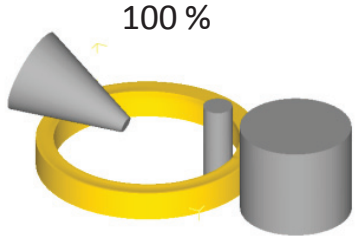

Figure 3: 3D-FE scheme of the ring rolling process model

All the tools were simulated as rigid bodies and between the rolls and the workpiece a shear friction factor equal to 0.7 was set typical of hot forging processes. The simulations were set as isothermal and the working temperature of all the case studies was set equal to $1150{ }^{\circ} \mathrm{C}$. The isothermal setting can be considered acceptable for two main reasons: first, because the cooling can be considered negligible due to the bulk dimensions of the workpiece (the starting bar weight is about 3.5 ton) and to the short time needed to deform it $(160 \mathrm{~s})$; second, because on the external ring surface the decrease of temperature is mitigated by the friction phenomena present on the involved surfaces. For determining the 
reliability of the developed model, a preliminary comparison with experimental values was carried out in a former work by comparing simulated and experimental results [12].

\section{Materials and Methods}

Tables 1 and 2 show the dimensions of the ring and rolls.

\begin{tabular}{|l|c|c|c|c|}
\hline Table 1: geometrical dimensions of the tested ring [mm] \\
\hline Geometry & $\mathrm{h}$ & $\mathrm{D}_{\text {ext }}$ & $\mathrm{D}_{\text {int }}$ & $\mathrm{W}$ \\
\hline Preform & 615 & 980 & 270 & 355 \\
\hline Final rolled ring & 509 & 2114 & 1844 & 135 \\
\hline Production time $[\mathrm{s}]$ & \multicolumn{5}{|c|}{160} \\
\hline
\end{tabular}

\begin{tabular}{|l|c|}
\hline \multicolumn{2}{|c|}{ Table 2: main roll dimensions } \\
\hline Idle Roll diameter [mm] & 245 \\
\hline Driver Roll diameter [mm] & 950 \\
\hline Axial Roll height [mm] & 1000 \\
\hline Axial Roll taper angle [grad] & $35^{\circ}$ \\
\hline
\end{tabular}

As said above the milling curve plots the instantaneous ring height $(\mathrm{H})$ as a function of the instantaneous ring width (W), that means the Axial roll displacement as a function of the Idle roll displacement. Since the Ring Rolling machine controls each roll displacement by imposing a speed law, the Idle and Axial roll speed equations must be derived from the milling curve. In order to investigate how the speed law trend affect the process different equations, characterized by a decreasing, constant or increasing linear trend, were introduced. In such a way, it is possible to understand if it is better to impose an high or constant or lower cross section reduction in the initial part of the deformation process. Based on this idea three different trends were designed for each roll:

- $\quad$ linearly decreasing (W-);

- constant (W0)

- $\quad$ linearly increasing $(\mathrm{W}+)$;
- $\quad$ linearly decreasing (H-);

- $\quad$ constant $(\mathrm{H} 0)$

- $\quad$ linearly increasing $(\mathrm{H}+)$;

The constant (W0/H0) condition; the W0/H0 speed law was simply calculated knowing the production time (160 s) and the initial and final geometry. In order to have significant variations the decreasing $(\mathrm{W}-/ \mathrm{H}-)$ and increasing $(\mathrm{W}+/ \mathrm{H}+)$ linear equation were evaluated imposing a starting value of the Idle roll speeds respectively increased or decreased by $50 \%$. Starting from these initial points, the curves were drawn considering the manufacturing of rings having the same final geometry with the same production time. The points defining the Idle and Axial roll speed law equations are reported in tables 3 and 4 .

\begin{tabular}{|c|c|c|c|}
\hline \multicolumn{4}{|c|}{ Table 3: fitted points for Idle roll speed equation $[\mathrm{mm} / \mathrm{s}]$} \\
\hline time $[\mathrm{s}]$ & $\mathrm{W}-$ & $\mathrm{W} 0$ & $\mathrm{~W}+$ \\
\hline 0 & 1.88 & 1.25 & 0.63 \\
\hline 160 & 0.63 & 1.25 & 1.88 \\
\hline
\end{tabular}

\begin{tabular}{|c|c|c|c|}
\hline \multicolumn{4}{|c|}{ Table 4: fitted points for Axial roll speed equation } \\
{$[\mathrm{mm} / \mathrm{s}]$}
\end{tabular}

From the speed law equation the 9 combinations of Idle vs Axial roll displacements (milling curves) were derived (figure 4).

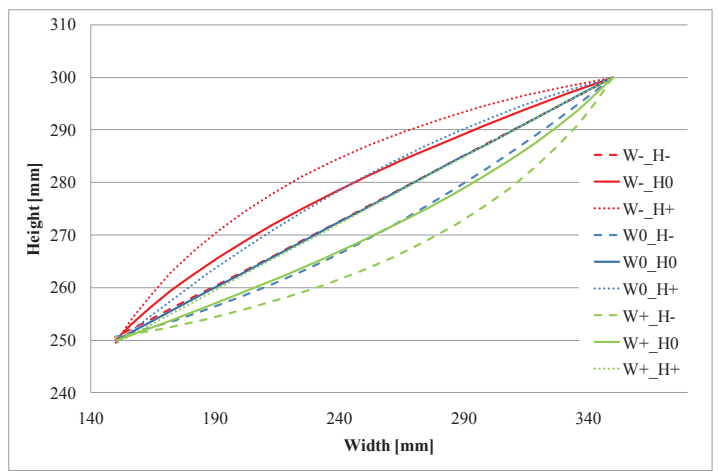

Figure 4: Milling curves modeled for the numerical campaign

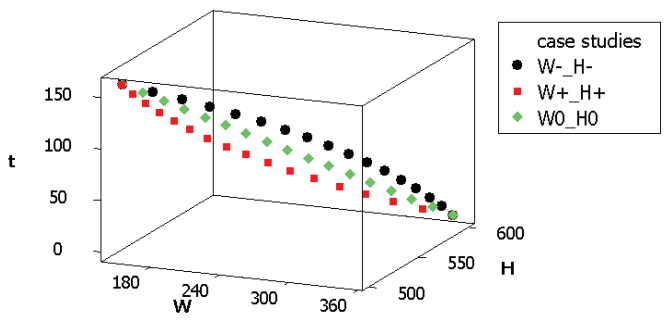

Figure 5: 3D graph of $\mathrm{W}-\mathrm{H}_{-}, \mathrm{W}+\mathrm{H}_{+}+$and $\mathrm{W} 0 \_\mathrm{H} 0$ milling curves

Even if, looking at figure 4 it seems that in some cases the same milling curves are obtained, it must be remembered that they differ one to each other for the time along which they evolve. As an example figure 5 reports the W-_H-, 
$\mathrm{W}+$ H+ and W0_H0 milling curves including the time axis; the difference is evident. For all the simulated case studies, the $\bar{D}$ river roll angular speed was set constant and equal to $3 \mathrm{rad} / \mathrm{sec}$. Table 5 resumes, for each test, the ring cross section as a function of time.

\begin{tabular}{l} 
Table 5: Ring cross section during process deformation \\
\hline \\
$\qquad$\begin{tabular}{|c|c|c|c|c|c|c|}
\hline $\mathrm{t}[\mathrm{s}]$ & $\mathrm{W}-$ & $\mathrm{W} 0$ & $\mathrm{~W}+$ & $\mathrm{H}-$ & $\mathrm{H} 0$ & $\mathrm{H}+$ \\
\hline 0 & 350 & 350 & 350 & 300 & 300 & 300 \\
\hline 40 & 281 & 300 & 319 & 283 & 288 & 292 \\
\hline 80 & 225 & 250 & 275 & 269 & 275 & 281 \\
\hline 120 & 181 & 200 & 219 & 258 & 263 & 267 \\
\hline 160 & 150 & 150 & 150 & 250 & 250 & 250 \\
\hline
\end{tabular}
\end{tabular}

\section{Simulation Results Analysis}

The results were compared to study if and how the proposed milling curves guarantee a precise ring (geometrical comparison) and their effect on the loads and energies required to carry out the process (physical comparison). The geometrical comparison considers the external diameter, the ring height, width and the fishtail defect in order to consider the cross section irregularities too. In particular:

- the ring width was estimated as the average value of four measures taken on the lower ring surface to avoid fishtail defect interference; each measure is taken with an angular step of $90^{\circ}$ (Fig. 6.a);

- the ring height, because of the fishtail generates an irregular ring shape, was evaluated as average value on five different circumference scans (from outer to inner) taken from the upper ring surface (Fig. 6.b);

- for the external diameter a cutting plane section orthogonal to $\mathrm{z}$ axis (130 $\mathrm{mm}$ from the symmetry plane) was created to avoid fishtail, the parameter was obtained as an indirect measure by calculating the external circumference value on the created upper ring section (Fig. 6.c);

- the fishtail defect, as introduced by the author in [13], was considered as a difference between the maximum and minimum ring height and was measured on the section pressed by the Idle and Driver roll where the defect assumes its maximum value (Fig. 6.d).

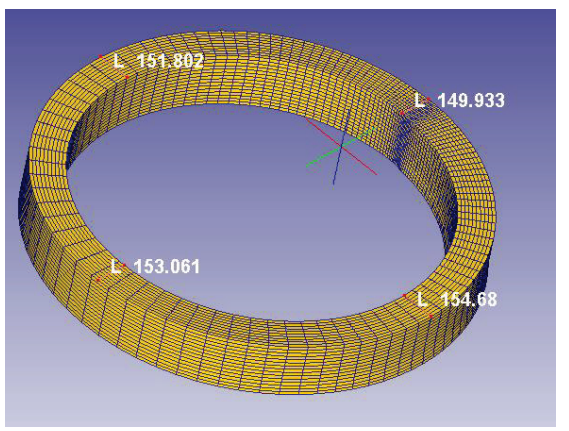

(a)

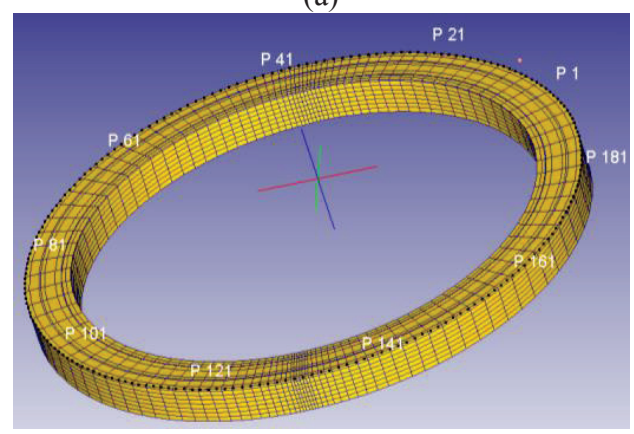

(c)

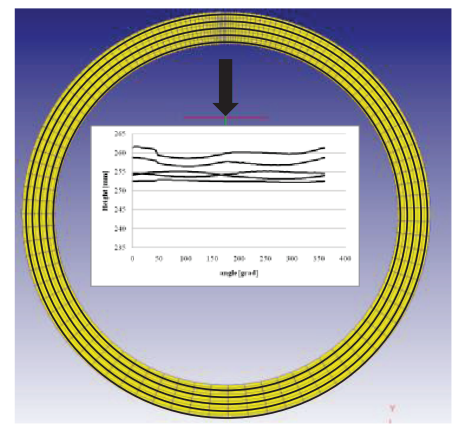

(b)

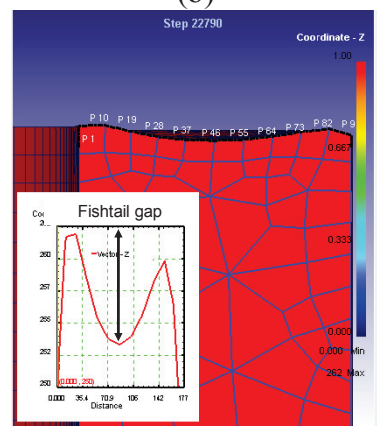

(d)

Figure 6: scheme of width (a), height (b), external diameter (c) and fishtail gap (d) measurement

Table 6 reports all the measurement results for all the simulated cases; the ring width and height are expressed in terms of average value $(\mu)$ and standard deviation $(\sigma)$. 


\begin{tabular}{|c|c|c|c|c|c|c|}
\hline \multicolumn{7}{|c|}{ Table 6: Final dimension of the simulated ring } \\
\cline { 2 - 7 } & & \multicolumn{2}{c|}{$\mathrm{H}[\mathrm{mm}]$} & \multicolumn{2}{c|}{$\mathrm{W}[\mathrm{mm}]$} & \\
\hline D_ext & $\mu$ & $\sigma$ & $\mu$ & $\sigma$ & Fishtail gap [mm] \\
\hline W__H- & 1904.3 & 511.3 & 5.41 & 151.3 & 1.56 & 18.5 \\
\hline W__H- & 1883.4 & 506.1 & 6.71 & 153.3 & 3.06 & 18.1 \\
\hline W__H- & 1877.9 & 504.5 & 4.95 & 154.8 & 4.05 & 15.4 \\
\hline W0_H0 & 1908.1 & 513.0 & 5.61 & 150.8 & 1.17 & 15.5 \\
\hline W+_H0 & 1900.6 & 507.8 & 6.19 & 152.4 & 2.03 & 15.7 \\
\hline W-_H+ & 1895.3 & 505.5 & 5.96 & 153.0 & 2.56 & 14.8 \\
\hline W0_H+ & 1913.0 & 512.6 & 5.26 & 150.9 & 1.18 & 16.8 \\
\hline W+_H+ & 1894.1 & 504.7 & 7.73 & 151.9 & 1.68 & 16.2 \\
\hline
\end{tabular}

Comparing these results with the desired final ring dimensions (Table 1), it is possible to state that a milling curve achieves good results when it is able to guarantee a higher external diameter and a lower ring height, width and fishtail gap. Analyzing the results, different considerations about the tested milling curves can be deducted:

- the Idle roll displacements, function of the different speed laws imposed, highly affect the ring quality and in particular:

○ a descending trend (W-) guarantees a higher external diameter and a lower ring width with a lower dispersion that is an indication of homogeneous ring;

$\circ \quad$ an increasing trend $(\mathrm{W}+)$ guarantees lower ring height and fishtail gap;

- the Axial roll displacement trend minimally affects the final ring dimensions; however, to impose an increasing trend $(\mathrm{H}+)$ helps the process in obtaining a higher external diameter and ring width, but, on the contrary, the ring height and fishtail gap quality become worst.

The physical parameters were analyzed taking into account the maximum Idle roll load, Axial roll load reached during the deformation and the Idle and Axial roll energy required by the process to deform it. The main results are summarized in Table 7.

\begin{tabular}{|c|c|c|c|c|}
\hline \multicolumn{5}{|c|}{ Table 7: Maximum Loads and Energies } \\
\hline & \multicolumn{2}{|c|}{ Max Load [N] } & \multicolumn{2}{c|}{ Energy [J] } \\
\cline { 2 - 5 } & Idle Roll & Axial Roll & Idle Roll & Axial Roll \\
\hline W__H- & $1.77 \mathrm{E}+06$ & $2.86 \mathrm{E}+06$ & $2.69 \mathrm{E}+05$ & $8.38 \mathrm{E}+04$ \\
\hline W0_H- & $1.62 \mathrm{E}+06$ & $2.93 \mathrm{E}+06$ & $2.68 \mathrm{E}+05$ & $9.29 \mathrm{E}+04$ \\
\hline W+_H- & $1.54 \mathrm{E}+06$ & $3.04 \mathrm{E}+06$ & $2.47 \mathrm{E}+05$ & $9.27 \mathrm{E}+04$ \\
\hline W__H0 & $1.68 \mathrm{E}+06$ & $2.30 \mathrm{E}+06$ & $2.74 \mathrm{E}+05$ & $7.61 \mathrm{E}+04$ \\
\hline W0_H0 & $1.57 \mathrm{E}+06$ & $2.33 \mathrm{E}+06$ & $2.63 \mathrm{E}+05$ & $8.25 \mathrm{E}+04$ \\
\hline W+_H0 & $1.52 \mathrm{E}+06$ & $2.61 \mathrm{E}+06$ & $2.64 \mathrm{E}+05$ & $8.70 \mathrm{E}+04$ \\
\hline W-_H+ & $1.76 \mathrm{E}+06$ & $1.97 \mathrm{E}+06$ & $2.80 \mathrm{E}+05$ & $7.32 \mathrm{E}+04$ \\
\hline W0_H+ & $1.62 \mathrm{E}+06$ & $2.03 \mathrm{E}+06$ & $2.74 \mathrm{E}+05$ & $8.17 \mathrm{E}+04$ \\
\hline W+_H+ & $1.58 \mathrm{E}+06$ & $2.12 \mathrm{E}+06$ & $2.52 \mathrm{E}+05$ & $8.10 \mathrm{E}+04$ \\
\hline
\end{tabular}

The target of the physical results analysis was focused on the minimization of the calculated parameters and the following considerations can be drawn:

- $\quad$ the Idle roll speed law mainly affects the maximum Idle load and the related energy; in particular:

$\circ \quad$ an increase in the speed law $(\mathrm{W}+)$ requires lower maximum load and energy for the Idle roll;

$\circ \quad$ a decrease in the speed law (W-) helps to decrease the required maximum load and energy for the Axial roll;

- the Axial roll speed law affects the related maximum load and energy; moreover, by imposing an increasing trends strategy $(\mathrm{H}+)$ the maximum Axial load and energy reduction is guaranteed;

As it can be observed from table 6 and 7 comparison, a combination of Axial and Idle roll speed laws optimizing all the process parameters investigated is not available. Therefore, in order to identify a Ring Rolling technological window, the following approach, based on interval partition, was taken into account by the authors:

- for each investigated parameter $x_{i}$ the range $r_{i}$ was evaluated equal to $x_{i \_ \text {min }}-x_{i_{-} \max }$;

- $\quad$ an interval $I_{i}=\left[x_{i_{-} \min ,}, x_{i_{-} \max }\right]$ was defined;

- $I_{i}$ was subdivided in three equidistant sub interval as a function of the range $r_{i}$; 
- depending on the specific parameter target (minimize or maximize) each sub interval was labeled as good, medium or poor;

- $\quad$ each parameter $x_{i}$ was classified according to the created sub interval.

In figure 7 the final matrix (giving a global point of view about the results) with all the parameters is reported as a function of the simulated Idle and Axial roll speed law.

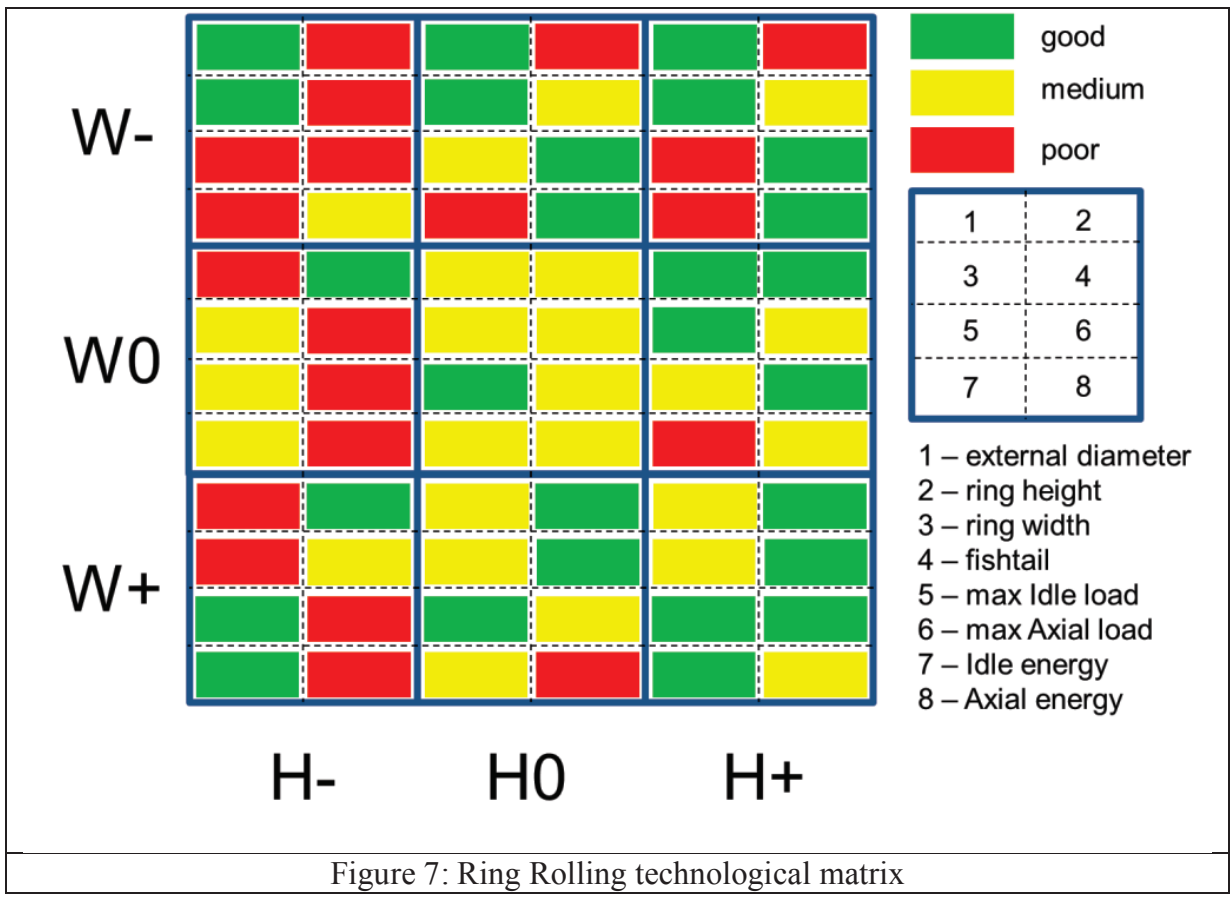

It is evident how a solution optimizing both geometrical and physical parameters is still not available. However, it is possible to assert that the rolls speed law characterized by an increasing trend $(\mathrm{W}+\mathrm{H}+)$ achieved the best results compared to the other test simulated. On the contrary, the W0_H+ solution could be designed if the target is the final ring quality.

\section{Conclusions}

In the present paper the influence of Idle and Axial the speed law trend were investigated. In particular the effect of the Idle and Axial roll linear speed laws was studied. These parameters are fundamental because they directly affect the process efficiency in terms of ring quality and maximum loads and energy required to realize the ring. The campaign results highlight that a set of rolls displacement able to optimize all the geometrical and physical parameters does not exist. However, best process conditions can be achieved by imposing an increasing speed law for the Idle and the Axial roll. Research activities are now ongoing to study the best increasing strategy (liner, quadratic, etc) in the roll speed law together with a cost model for realizing a more robust optimization analysis.

\section{References}

[1] Lin H., Zhi Z.Z., Journal of Materials Processing Technology. 69:273-276 (1997).

[2] Yan F.L., Hua L., Wu Y.Q., International Journal of Machine Tools \& Manufacture. 47:1695-1701 (2007).

[3] Anjami N., Basti A., Journal of Material Processing Technologies. 210:1364-1377 (2010).

[4] Wang Z.W., Fan J.P., Hu D.P., Tang C.Y., Tsui C.P., International Journal of Mechanical Sciences. 52:1325-1333 (2010).

[5] Zhou G., Hua L., Qian D., Shi D., Li H., International Journal of Mechanical Sciences. 59:1-7 (2012).

[6] Guo L., Yang H., International Journal of Mechanical Sciences. 53:286-299 (2011).

[7] Zhu S., Yang H., Guo L., Hu L., Chen X., International Journal of Advanced Manufacturing Technology, 72:5768 (2014).

[8] Parvizi A., Abrinia K.A., International Journal of Mechanical Sciences, 79:176-181 (2014).

[9] Giorleo L., Ceretti E., Giardini C., International Journal of Mechanical Sciences, 74:55-64 (2013).

[10] Lee K.H., Kim B.M., International Journal of Mechanical Sciences, 76:21-32 (2013).

[11] Giorleo L., Ceretti E., Giardini C., Key Engineering Materials, 622-623:956-963 (2014).

[12] Giorleo L., Giardini C., Ceretti E., International Journal of Material Forming, 6:145-152 (2013).

[13] Giorleo L., Ceretti E., Giardini C., Proceedings of NAMRI/SME 40 (2012). 